\title{
Microstructurally small fatigue crack growth rates in aluminium alloys for developing improved predictive models
}

\author{
Madeleine Burchill ${ }^{1, *}$, Simon Barter ${ }^{1}$, Lok Hin Chan $^{2}$, Michael Jones ${ }^{3}$ \\ ${ }^{1}$ Defence Science and Technology Group, Fishermans Bend, VIC, Australia \\ ${ }^{2}$ Hong Kong University of Science and Technology, Hong Kong \\ ${ }^{3}$ Fortburn PTY, LTD, Wendoree, VIC, Australia
}

\begin{abstract}
The fatigue or durability life of a few critical structural metallic components often sets the safe and/or economic useful life of a military airframe. In the case of aluminium airframe components, growth rates, at or soon after fatigue crack nucleation are being driven by near threshold local cyclic stress intensities and thus are very low. Standard crack growth rate data is usually generated from large cracks, and therefore do not represent the growth of small cracks (typically $<1 \mathrm{~mm}$ ). Discussed here is an innovative test and analysis technique to measure the growth rates of small cracks growing as the result of stress intensities just above the cyclic growth threshold. Using post-test quantitative fractographic examination of fatigue crack surfaces from a series of 7XXX test coupons, crack growth rates and observations of related growth phenomenon in the threshold region have been made. To better predict small crack growth rates under a range of aircraft loading spectra a method by which standard material data models could be adapted is proposed. Early results suggest that for small cracks this method could be useful in informing engineers on the relative severity of various spectra and leading to more accurate predictions of small crack growth rates which can dominate the fatigue life of airframe components..
\end{abstract}

\section{Introduction}

The life of type (LOT) of a military airframe in service maybe based on the fatigue or durability life of a few critical structural metallic components, due to safety and/or maintainability concerns [1]. In the case of aluminium alloy aircraft structures, it has been found that the fatigue life is dominated by the initial growth rate of the lead crack in any component, i.e. the crack that leads to the component failure [2]. The majority of the component's fatigue life is therefore consumed while such cracks are small $[3,4]$, and of the dimensions of the microstructure; typically nucleating from small naturally occurring material discontinuities, with an equivalent initial crack size, $a_{i}$ of $\sim 20 \mu \mathrm{m}$ [5]. For many airframe aluminium alloys, microstructurally small fatigue cracks initially have very low growth rates; when loaded with representative load spectra. These low growth rates are often being driven by near threshold local cyclic stress intensities $(\Delta \mathrm{K})$, and are not well represented by standard fatigue lifing methodologies, further such methods often under estimate growth rates in this regime [6-8], resulting in un-conservative fatigue life predictions.

One reason for this discrepancy is that standard crack growth rate data is usually generated from much larger cracks by methods such as those set out in the ASTM E647 "Standard test method for measurement of fatigue

Corresponding author: Madeleine.Burchill@dst.defence.gov.au crack growth rates" [9] and as a result, they do not represent the growth of small cracks (typically $<1 \mathrm{~mm}$ ).

A range of different strategies to develop accurate models of small crack growth, in particular for critical aircraft structural components, have been investigated. These include:

- assuming plasticity induced crack closure on the measured long crack data and adjusting the predicted growth for this [i.e. adjusted compliance ratio] [7];

- correlating crack growth to the crack tip opening displacement parameter [10];

- predicting formation of dislocations ahead of the crack front to correlate with crack growth [11];

- adjusting the effective threshold down [12];

- assuming exponential growth and a very low (or zero) growth threshold [13];

- determining a critical strain/distance threshold based on local notch/crack geometry $[14,15]$; and

- using the average crack growth for spectra that contain repeating blocks of variable loading, [16].

The Threshold and Small Crack (TASC) research program at DST has used another approach: an innovative test and analysis technique to directly measure the crack growth rates of small cracks growing as the result of stress intensities just above the cyclic threshold region $\left(\Delta \mathrm{K}_{\mathrm{th}}\right)$. Here, the method applies a loading spectrum that includes alternating constant amplitude (CA) load sub-blocks, to small aluminium alloy test specimens. Post-test microscopy of the fracture 
surfaces, using both optical and electro-optical inspection allows the crack growth rates to be measured from the CA growth bands. Such measurements include growth rates well below the standard threshold values typically published using other measurement techniques.

This paper outlines the TASC test and analysis process, and other interesting results, particularly the subtle crack growth retardation associated with CA only loading as well as general retardation and acceleration phenomena. A new data model of the crack growth rate was also developed from the data generated in this test program. Finally, a validation of the crack growth data model is presented to predict a fatigue crack growth in similar coupons that were tested with a variable amplitude (VA) spectrum.

\section{Measuring Threshold Crack Growth}

The TASC methodology has been previously reported, including in [17] where a brief synopsis of one principle methodology employed was given to measure near threshold and small crack growth. This is reproduced below, along with a material crack growth data model informed by this TASC data for AA7050-T7451. The TASC program at DST aims to:

- improve DST's fatigue crack growth predictive capacity and tools to support the Australian Defence Force capability, and

- improve general understanding of the retardation/acceleration mechanisms present in the fatigue cracking process and their various sources.

\subsection{General Test and Analysis Methodology}

The TASC coupon testing program uses specially engineered novel test spectra that combine small sequences or sub-blocks of CA and VA loading. An example of a normalised TASC spectrum is shown as an insert in Fig. 1, where this load spectrum was used to generate crack growth data for two load (stress, $\sigma$ ) ratios, $\mathrm{R}\left(\sigma_{\min } / \sigma_{\max }\right): \mathrm{R}=0.5$ and $\mathrm{R}=-0.5$ and produced the fracture surface shown in Fig 1. Here, the normalised spectrum is scaled to achieve $180 \mathrm{MPa}$ net peak stress in the test region. The coupons were tested to failure after which the fracture surfaces were inspected using the following quantitative fractography methods: optical microscopes were used with magnifications up to X1000 to measure crack growth increments as small as $1 \mu \mathrm{m}$ in width. Field emission electro-optical scanning electron microscopes (FEGSEM) were used for higher levels of magnification, where crack growth increments as small as $20 \mathrm{~nm}$ could be measured. A typical FEGSEM image of the fracture surface at a small crack depth $(\mathrm{a} \sim 0.4 \mathrm{~mm})$ is also given in Fig. 1, showing the differences crack growth topography that can be observed at this scale from testing with the spectrum shown in the figure.

The content of the CA and VA sub-blocks in each TASC spectra was selected to ensure the growth bands could be identified. Depending upon the material to be tested, some trial-and-error is required to ensure good visibility. In particular it is worth noting, and can be seen in Fig. 1 that the incorporation of the $\mathrm{VA}^{\mathrm{a}}$ sub-block greatly aided identification of CA growth bands on the fracture surface by producing topography and growth plane differences [18].

Test coupons are (typically) of a hour-glass shape with a large radius and thus a low net stress concentration, $(\mathrm{Kt})$ with the dimensions given in Table 1 . To ensure fatigue cracks nucleated in the test region, the coupon surfaces were prepared in one of two ways, either: (i) etched entirely and shot-peened outside of the test area or (ii) polished all over and laser slotted [19] within the test area.

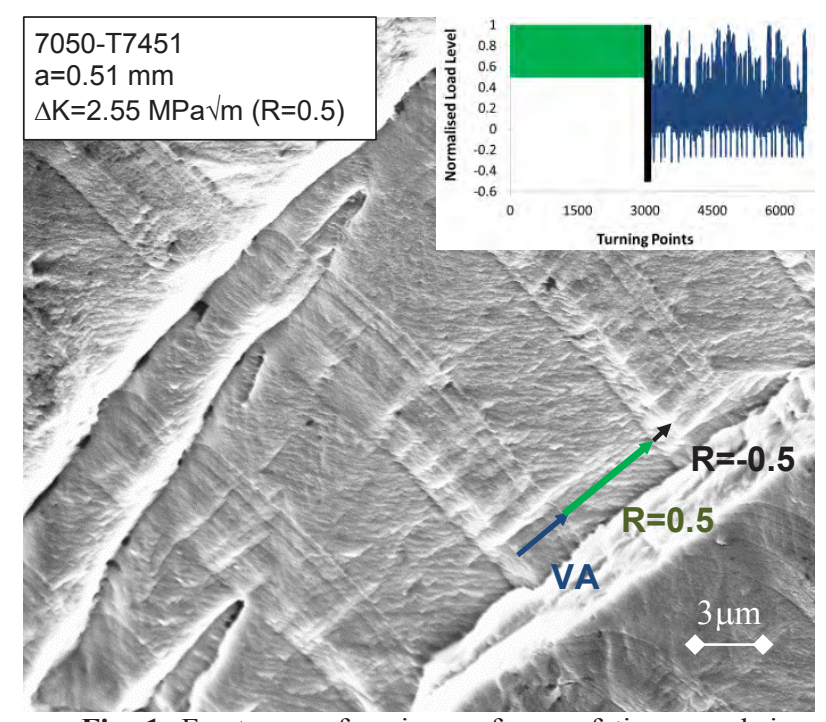

Fig. 1. Fracture surface image from a fatigue crack in a AA7050-T7451 coupon tested with the spectrum shown in the insert; topography differences are used to identify growth from $\mathrm{CA}(\mathrm{R}=0.5$ and $\mathrm{R}=-0.5)$ and VA load sub-blocks.

Table 1. Dimension details of hour-glass coupons (mm)

\begin{tabular}{|c|c|c|c|c|c|c|}
\hline \multicolumn{3}{|c|}{ overall dimensions } & \multicolumn{4}{c|}{ test (net) section } \\
\hline length & width & $\begin{array}{c}\text { thick- } \\
\text { ness }\end{array}$ & radius & width & $\begin{array}{c}\text { Kt } \\
\text { net }\end{array}$ & $\begin{array}{c}\text { Kt } \\
\text { gross }\end{array}$ \\
\hline 160 & 40 & 6.35 & 100 & 25 & 1.08 & 1.73 \\
\hline
\end{tabular}

\subsection{Crack growth rate data}

Crack growth rate data $(\mathrm{da} / \mathrm{dN})$ for small fatigue cracks in AA7050-T7451 has been collected from 20 coupons, tested with TASC spectra, shown in Fig. 1 for $\mathrm{R}=0.5$ only, or from similar spectra for $\mathrm{R}=0.1$ and $\mathrm{R}=0.8$ as reported in [17]. This data is presented in Fig. 2 along with the standard material curve taken from the a linear elastic fracture mechanics crack growth data included with AFGROW [20]. Here it can be seen that the TASC method enables the measurement of crack growth well below the standard threshold $\Delta \mathrm{K}$ and at lower rates of growth than can be measured using those long crack standard techniques.

Table 2 provides a summary of a material data set for three R values developed by DST (referred to as DST16)

\footnotetext{
${ }^{\text {a }}$ Segments of a sequence from an aircraft wing root bending moment loading spectrum are used, such as the industry standard TWIST or FALSTAFF
} 
that was designed to allow prediction of the growth of small cracks in AA7050-T7451, informed by the TASC data. Validation studies have shown that these curves when used with a crack growth algorithm, such as that in AFGROW, with no closure (retardation) model activated, predicts well coupons tested with VA spectra based on combat aircraft wing root bending moment loading [21]. However for VA spectra, that contained significant number of cycles with high mean and small amplitude $^{\mathrm{b}}$ (e.g. $\mathrm{R}=0.8$ ), the DST16 model did not correlate as well. The following sections detail research undertaken to investigate how crack growth is influenced by prior load cycles, such as long sequences of loading that approximates $\mathrm{CA}$.

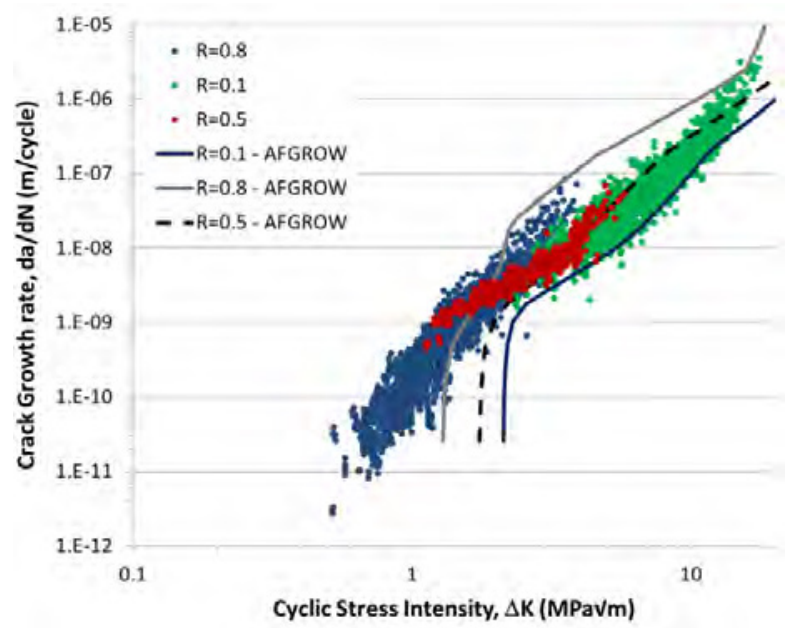

Fig. 2. Crack growth data generated during the TASC program for AA7050-T7451 coupons and standard (AFGROW) growth models.

Table 2. Crack growth rate data set (DST16) for aluminium alloy AA7050-T7451 at $\mathrm{R}=0.1, \mathrm{R}=0.5$ and $\mathrm{R}=0.8$.

\begin{tabular}{|c|c|c|c|}
\hline \multirow{2}{*}{$\begin{array}{c}\text { da/dN } \\
\text { (m/cycle) }\end{array}$} & \multicolumn{3}{|c|}{ Cyclic Stress Intensity, } \\
& $\mathrm{K}=0.1$ & $\mathrm{M}=0.5$ & $\mathrm{R}=0.8$ \\
\cline { 2 - 4 } & $\mathrm{m}=\mathbf{\text { }}=\mathbf{}$ \\
\hline $1.00 \mathrm{E}-12$ & 0.5720 & 0.5165 & 0.4745 \\
\hline $2.00 \mathrm{E}-12$ & 0.5723 & 0.5168 & 0.4749 \\
\hline $5.00 \mathrm{E}-12$ & 0.5738 & 0.5182 & 0.4762 \\
\hline $1.00 \mathrm{E}-11$ & 0.5747 & 0.5190 & 0.4770 \\
\hline $2.00 \mathrm{E}-11$ & 0.5759 & 0.5202 & 0.4781 \\
\hline $5.00 \mathrm{E}-11$ & 0.5772 & 0.5215 & 0.4794 \\
\hline $1.00 \mathrm{E}-10$ & 0.5779 & 0.5221 & 0.4799 \\
\hline $2.00 \mathrm{E}-10$ & 0.8034 & 0.6864 & 0.5914 \\
\hline $5.00 \mathrm{E}-10$ & 1.2171 & 1.0153 & 0.8598 \\
\hline $1.00 \mathrm{E}-09$ & 1.6988 & 1.4011 & 1.1692 \\
\hline $2.00 \mathrm{E}-09$ & 2.3705 & 1.8951 & 1.5768 \\
\hline $5.00 \mathrm{E}-09$ & 3.6720 & 2.7516 & 2.3019 \\
\hline $1.00 \mathrm{E}-08$ & 5.1016 & 3.7316 & 3.1078 \\
\hline $2.00 \mathrm{E}-08$ & 6.9502 & 5.0564 & 4.2937 \\
\hline $5.00 \mathrm{E}-08$ & 10.4032 & 6.9159 & 5.7607 \\
\hline $1.00 \mathrm{E}-07$ & 13.7856 & 8.7249 & 6.7573 \\
\hline $2.00 \mathrm{E}-07$ & 17.9561 & 10.8514 & 7.8065 \\
\hline $5.00 \mathrm{E}-07$ & 23.7728 & 13.7536 & 9.0629 \\
\hline
\end{tabular}

${ }^{\mathrm{b}}$ for example blade-pass loading in rotor aircraft or highly dynamic (buffet) loading on combat aircraft structures

\section{Growth Retardation and Acceleration}

\subsection{Retardation from repeated $\mathrm{R}=0.8$ cycles}

Previously DST [22] has reported on small crack growth retardation with increasing number of $\mathrm{CA}$ cycles. Evidence of this phenomenon was observed in the measured crack growth rates from a series of coupons tested with the TASC methodology. In this research, identical AA7050-T7451 coupons to those used in the above work, were tested with a spectrum that included CA $\mathrm{R}=0.8$ sub-blocks with varying numbers of cycles (N). Fig. 3 is an example of a typical fatigue crack fracture surface, with the TASC spectrum shown in the insert, here the peak load was scaled to achieve $200 \mathrm{MPa}$ at the net test section. From measurements of nine coupons tested in this study, the changes in average crack growth with increasing $\mathrm{R}=0.8$ cycles can be determined. A summary of such data is presented in Table 3, where such a trend can be seen, for example at a $\Delta \mathrm{K}=1.00 \mathrm{MPa} \sqrt{\mathrm{m}}$, the growth of the 5000th $\mathrm{R}=0.5 \mathrm{load}$ cycle will be approximately half that of the 500th load cycle.

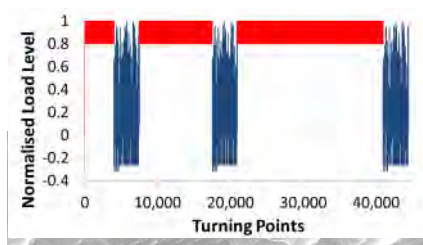

7050-T7451

$\mathrm{a}=0.63 \mathrm{~mm}$

$\Delta \mathrm{K}=1.29 \mathrm{MPa} \sqrt{\mathrm{m}}(\mathrm{R}=0.8)$
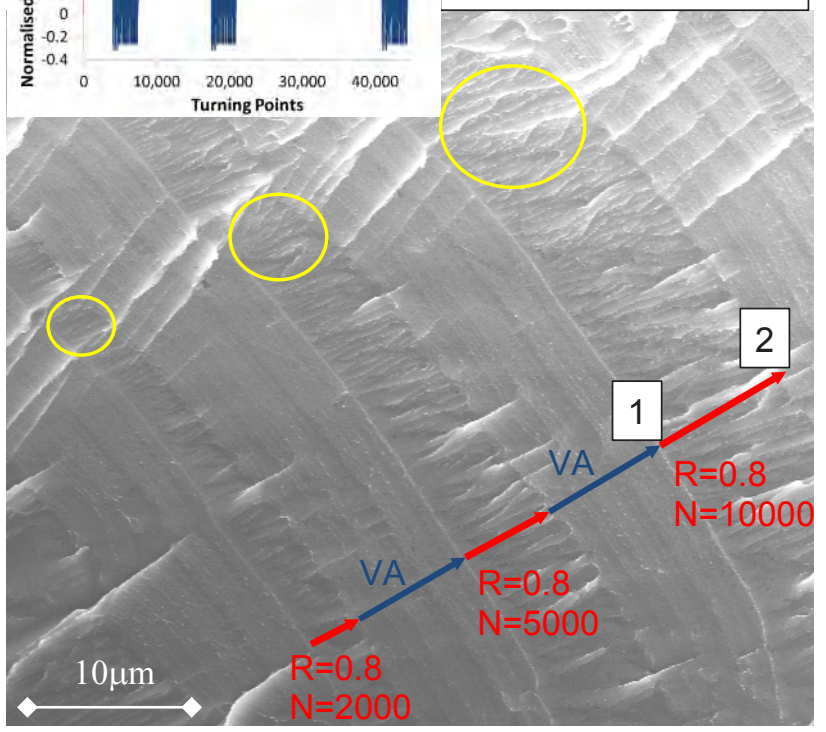

Fig. 3. Fracture surface image from a fatigue crack in a AA7050-T7451 coupon, showing micro-river patterns (circled) the crack front produced under VA loading (labelled 1) and $\mathrm{R}=0.8$ CA loading (labelled 2). 
Table 3. Average crack growth rates (nanometres/cycle) for increasing $\mathrm{R}=0.8 \mathrm{CA}$ cycles $(\mathrm{N})$

\begin{tabular}{|c|c|c|c|c|c|}
\hline \multirow{2}{*}{$\begin{array}{c}\Delta \mathbf{K} \\
\mathbf{M P a} \sqrt{ } \mathbf{m}\end{array}$} & \multicolumn{6}{|c|}{ Average Crack Growth Rates $(\mathbf{d a} / \mathbf{d N}), \mathbf{n m} /$ cycle } \\
\cline { 2 - 6 } & $\mathrm{N}<500$ & $\begin{array}{c}500< \\
\mathrm{N} \\
<1,000\end{array}$ & $\begin{array}{c}1,000< \\
\mathrm{N}\end{array}$ & $\begin{array}{c}2,000< \\
\mathrm{N}\end{array}$ & $\begin{array}{c}5,000< \\
\mathrm{N}\end{array}$ \\
\hline 0.60 & 0.105 & 0.032 & 0.057 & 0.040 & 0.031 \\
\hline 0.80 & 0.253 & 0.105 & 0.144 & 0.112 & 0.080 \\
\hline 1.00 & 0.499 & 0.254 & 0.296 & 0.247 & 0.170 \\
\hline 1.50 & 1.721 & 1.192 & 1.090 & 1.029 & 0.659 \\
\hline 2.00 & 4.139 & 3.464 & 2.747 & 2.831 & 1.726 \\
\hline 3.00 & 14.261 & 15.131 & 10.103 & 11.738 & 6.696 \\
\hline \multicolumn{7}{|c|}{} \\
\hline
\end{tabular}

It is hypothesised that, in the case of small cracks, repeating high $\mathrm{R}$ (e.g. $\mathrm{R}=0.8$ ) load cycles are insufficient to maintain a continuous consistent crack front (labelled 2 in Fig. 3). On the local scale, the crack follows varying paths though the material influenced by the local microstructure, crack orientation and the damage state ahead of the crack tip. As a result, this may be one subtle mechanism, of several, that reduces growth efficiency and therefore growth rates. Other possible evidence of this is highlighted (circled) in Fig.3; in the variation in the fracture surface from crack growth under CA R $=0.8$ load cycles where micro-river patterns form as the crack front separates and re-joins. Compare this to the smoother fracture surface that results from crack growth under $\mathrm{CA} \mathrm{R}=0.1$ and VA loading.

\subsection{Retardation from repeated $\mathrm{R}=\mathbf{0} . \mathbf{5}$ cycles}

The retardation results were even more striking from a similar series of coupons tested with spectrum containing sub-blocks of $\mathrm{CA} R=0.5$ cycles with varying load cycles. This test spectrum is shown insert in Fig.4, where it should be noted that the $\sigma_{\max }$ of each CA subblock is less than $\sigma_{\max }$ of the VA sub-block. In this case, as shown in the fracture surface image in Fig.4, crack growth where the crack growth is observed to essentially stop for increasing $\mathrm{N}$ (i.e. the CA growth bands appear to be of the same width regardless of $\mathrm{N}$ ).

The average crack growth rate data collected from two coupons tested (with the spectrum shown insert in Fig. 4), is shown in Fig. 5. In this figure the variation in average growth rate between the different length $\mathrm{R}=0.5$ CA sub-blocks; of 2000, 5000 and 10000 cycles can be seen. Observed in this data, are the significant differences between the average crack growth rates during each CA sub-block of loading up to $\Delta \mathrm{K} \sim 2.2 \mathrm{MPa} \sqrt{\mathrm{m}}$. Since no difference was observed on the fracture surface in the wake of these CA sub-block growth bands, plastic-wake induced closure is not considered to be the cause of the apparent retardation. Rather the growth within the CA bands appears to hit- $a$ wall or slow to a very slow rate. Noting that grain boundaries may often create barriers for crack growth, observations of the fracture surfaces ruled out this potential cause.

For crack lengths greater than $1.5 \mathrm{~mm}(\Delta \mathrm{K} \sim$ $2.2 \mathrm{MPa} \sqrt{\mathrm{m}})$, no retardation effect could be identified in this data from repeated $\mathrm{R}=0.5$ cycles. This could be the result of larger cracks being less influenced by local microstructural variations (e.g. crystalline orientation) compared to smaller cracks. Also shown in Fig. 5 is the $\mathrm{R}=0.5$ curve from the DST $16^{\mathrm{c}}$ material model (Table 2 ), as this model has been optimised for combat aircraft wing root bending (VA) load spectra, thus this curve could be considered the rate for a single $\mathrm{R}=0.5$ load cycle of a lead crack (i.e. fastest predicted).

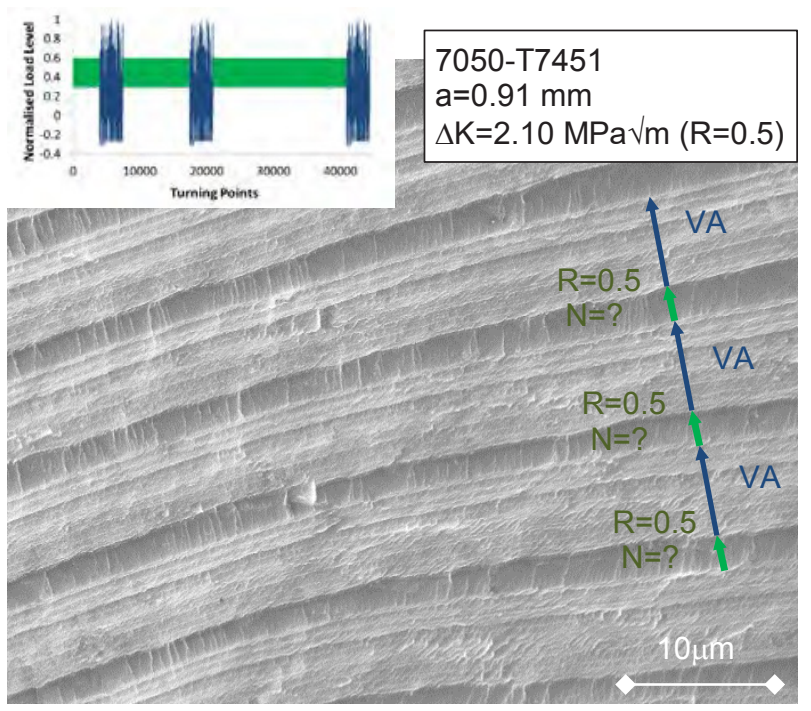

Fig. 4. Fracture surface images from a fatigue crack in a AA7050-T7451 coupon, a $=0.91 \mathrm{~mm}$, showing evidence of crack growth retardation; individual $\mathrm{CA} R=0.5$ sub-block cannot be identified (labelled $\mathrm{N}=$ ?).

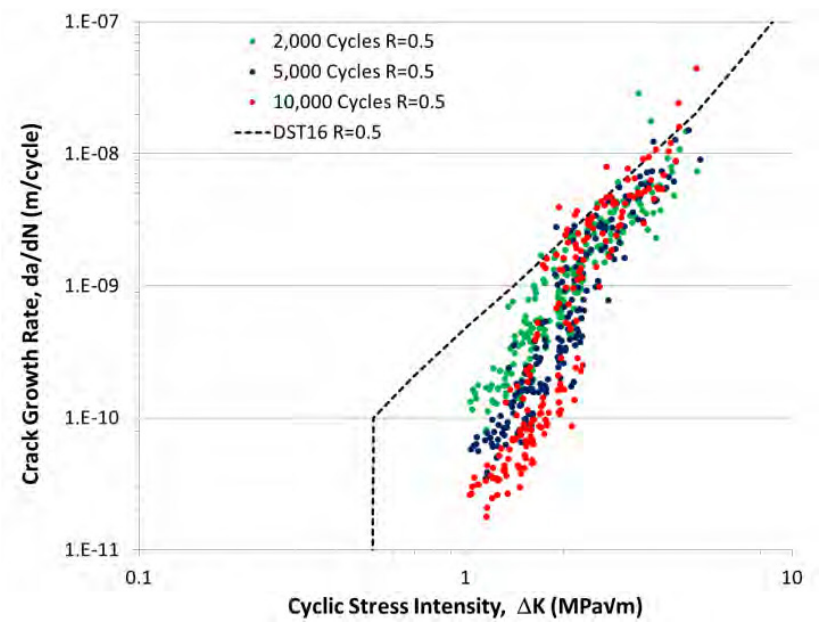

Fig. 5. Variation in average crack growth from $\mathrm{R}=0.5 \mathrm{CA}$ sub-blocks (insert Fig.4) for $\mathrm{N}=2000,5000$ and 10000 cycles. Compared to DST16 crack growth model (Table 2 for $\mathrm{R}=0.5$ ).

\subsection{Acceleration from underloads $R=-1.0$ cycles}

Further coupon testing was undertaken to investigate the extent to which the preceding load cycles influence the subsequent crack growth rates. In the case of the

\footnotetext{
${ }^{c}$ the DST16 material model (Table 2) was optimised to predict small crack growth for a sub-set of aircraft wing root bending moment loading. Validation of this model, including the threshold limit $\Delta \mathrm{K}_{\mathrm{th}}$, was made against a different VA data set [21].
} 
spectrum shown in Fig.4, it was noted that the VA sequence, with a higher peak load, $\sigma_{\max }$ could influence the retardation effect measured in the following CA subblocks. To investigate this, another series of coupons were tested with under-loads, i.e. $\sigma_{\min }<0$ applied to the specimen prior to the application of each CA sub-block. Either; one, four or ten under-loads of $\mathrm{R}=-1.0$ were applied.

As expected [23] the presence of underloads had a significant effect on the crack growth; possibly through the creation of alternate crack paths that promote crack front cohesion [19], or other mechanisms such as a reduction in the effective stress intensity [24]. Regardless, the effect on the crack growth rate can be directly measured over a range of crack lengths. An example of such measurements is shown below in Fig. 6, on the average growth rate from the 10,000 cycle $\mathrm{R}=0.5$ CA sub-block without under-loads (No UL) compared to that with ten preceding under-loads (10 UL). This data is typical of that observed in the range of coupons tested in this program, with the underload effect being dependent upon the crack length (therefore $\mathrm{K}_{\max }$ ), and most pronounced in the threshold $\Delta \mathrm{K}$ region. Of note in Fig. 6 is the effect of underloads on the longer crack growth rates, which are greater than would be predicted by the DST16 model.

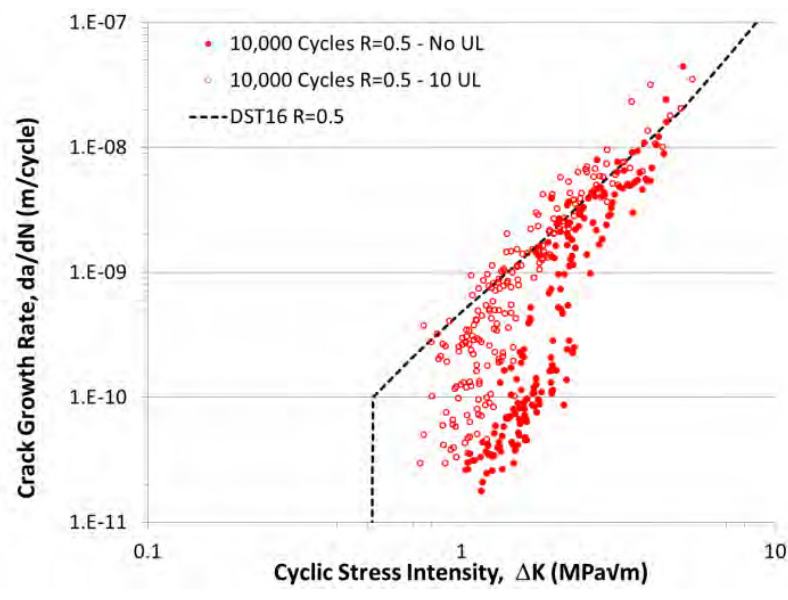

Fig. 6. Variation in average crack growth from 10,000 $\mathrm{R}=0.5$ load cycles - both with and without 10 under-loads (insert Fig.4) applied prior. Compared to DST16 crack growth model (Table 2 for $\mathrm{R}=0.5$ )

\section{Predicting Small Cycle Retardation}

As discussed above while, the DST16 material data model was found to be good at predicting small crack growth from a range of $\mathrm{VA}^{\mathrm{d}}$ loading; the model did not predict well those spectra that contained load sequences that contained load sequences approximating high R CA loading. A small study was undertaken to explore a method by which crack growth model data (e.g. Table 2)

\footnotetext{
${ }^{d}$ it should be noted that typical aircraft spectra used for validation testing based on recorded flight data will often require spectrum manipulation such as rainflow counting to create a sequence of minimum-maximum load turning points.
}

could be used to predict small crack growth for a larger range of VA spectra types. It also may provide a method by which a comparison of spectrum truncation or filtering processes can be made to support full scale test activities at DST.

For this work a modified material model was proposed, based on DST16, whereby the growth rate was varied as a function of the number of the repeated small cycles applied prior to the current cycle. An example of the output from such a function for $\mathrm{R}=0.8$ is shown below in Fig. 7, along with the DST16 material model curve and the $\mathrm{R}=0.8 \mathrm{TASC}$ test data. In this figure are the proposed crack growth rates after 1, 500 and 10000 $\mathrm{R}=0.8$ cycles.

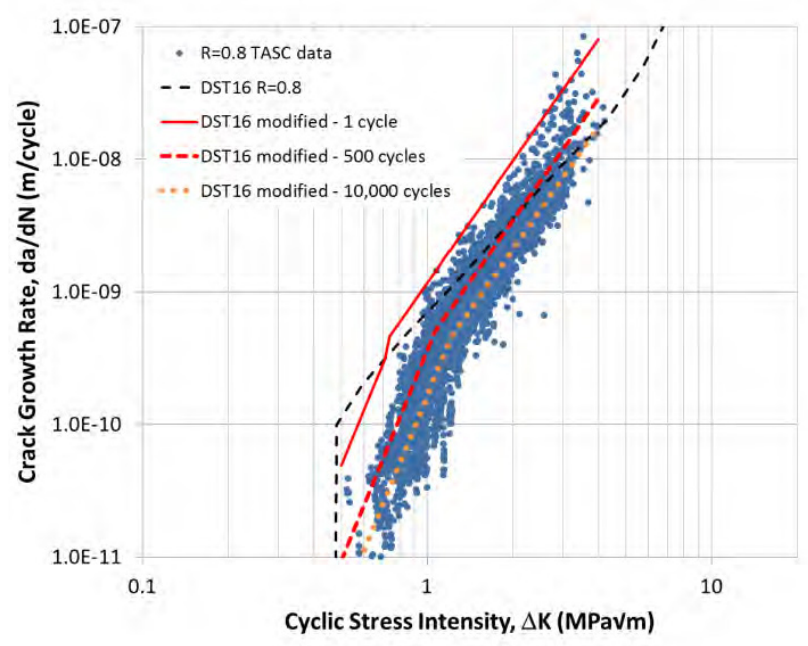

Fig. 7. Modification to $\mathrm{R}=0.8$ DST16 model material model (Table 2) for repeated cycles.

To assess the validity of this method, crack growth data results from an associated small fatigue test coupon were used [19]. In this program, five coupons of identical material and design as those discussed above were tested with a spectrum, shown as an insert in Fig.8. This spectrum was designed to allow the direct measurement of how sequence order within a VA spectrum influences crack growth. Shown in Fig. 8, the spectrum includes: a VA sequence based of a combat aircraft wing root bending moment with $1000 \mathrm{R}=0.8$ cycles intertwined (blue), the same VA sequence and $1000 \mathrm{R}=0.8$ cycles blocked (red), and an additional sequence of $\mathrm{R}=0.8$ cycles (green) used to aid post-test inspection - a marker band.

Small crack growth results from the coupon tests (Fig. 8) showed that the intertwined spectrum (blue points) resulted in faster crack growth than the block spectrum (red points). Over the range of the small crack depths measured here $(0.3-5.0 \mathrm{~mm})$ the intertwined spectrum is determined to be approximately $24 \%$ more severe than the blocked spectrum. Predictions based on the DST16 material data that included a retardation function based on cycle count is shown in Fig.8. Here the modification resulted in the intertwined spectrum being predicted to be $19 \%$ (in terms of crack growth rates) more severe than the blocked spectrum. This compares to the un-modified DST16 model that only predicted a difference of $3 \%$ between the spectra for 
small crack growth rates. (Only the un-modified DST16 model for the intertwined crack growth is shown in Fig.8 since the blocked result is almost identical and hard to differentiate at this scale).

This result suggests that accounting for retardation effects associated with repeated small load cycles may improve the accuracy of prediction of small crack growth rates under certain VA load spectra. It should be noted that a growth model should also include other load history effects (e.g. under- and over-loads) to enable robust crack growth predictions for VA spectra.

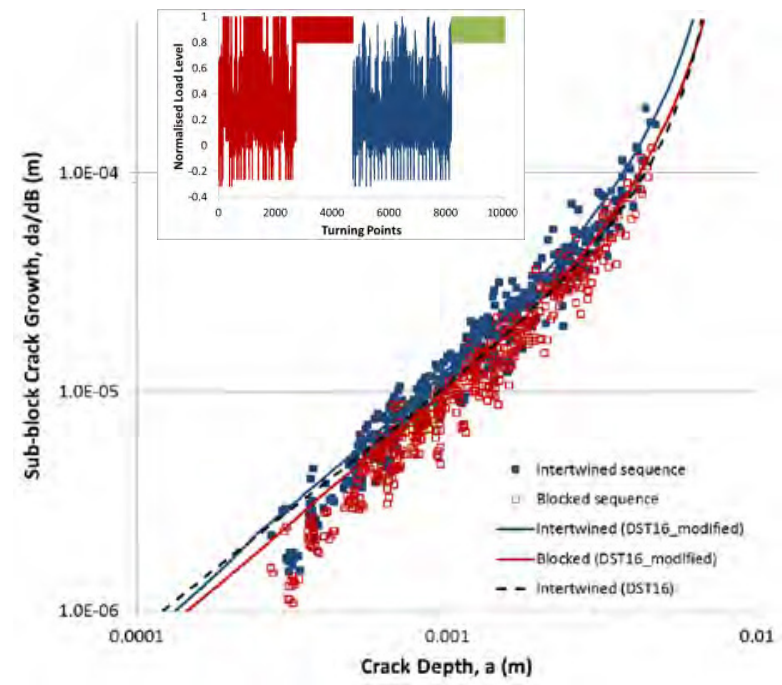

Fig. 5. Improved correlation from the modified DST16 model.

\section{Discussion}

Shown in the results presented here are the significant influences that load sequence has on crack growth rates of small cracks in AA7050-T7451. Of particular interest to DST is the effect that repeated small amplitude cycles, with a high mean, has in retarding crack growth in the threshold region. Due to the inherently exponential crack growth rates $[2,25]$ observed in common airframe alloys under aircraft loading, retardation of growth at the very early stages of fatigue nucleation/growth can have a significant impact on the total fatigue life of a component. A modification to a material model for AA7050-T7451 has been developed that accounts for such a subtle crack growth retardation produced by the use of CA cycles when blocked.

Further, in the threshold region, the use of crack growth data models to predict variable loading such as that occurring in aircraft platforms should not be based on data derived from CA testing only. Noting that the effect of overloads to crack growth has long been investigated since there is significant retardation from the assumed large compressive yield zones that result from overloads. Less well recognised is the acceleration in growth that can occur, and observed here in the threshold region, when significant underloads are applied. This may be another reason CA crack growth data is a poor predictor of fatigue growth for small cracks under VA spectra, such as aircraft wing root bending moment loading. Such VA spectra often contain cycles with compressive loads which, suggested by the results presented here, may result in the increased effectiveness of subsequent small load cycles in growing the crack.

Finally, when truncation or spectrum blocking are required (often to ensure efficient testing) for validation activities, the results suggest that the application of relatively large underloads when applied prior to a sequence of CA load cycles, can result in a significant reduction in the retardation.

\section{Conclusion}

Undertaking quantitative fractographic examination of fatigue crack surfaces that have been tested with specially engineered load sequences has enabled DST to accurately measure threshold crack growth rates and correlate growth retardation and acceleration measurements with load events. One phenomenon explored was, where loading spectra contain sequences of many ('000's) small amplitude/high mean cycles, crack growth retardation for small cracks that was identified as a possible reason for poor correlation with traditional predictive algorithms. (The influence on crack growth rates from repeated small cycles by the prior application of an underload was also discussed.) To better predict this retardation a method has been proposed by which standard material data models for crack growth could be adapted. Early results suggest that for small cracks this method could be useful in informing engineers on the relative severity of various loading spectra. This could have direct consequences for validation testing through full scale fatigue tests, to reduce the likelihood of un-conservative findings through the removal of too many small load cycles from spectra or the use of blocked spectra which may result in un-representative loading.

\section{References}

1. MIL-HDBK-1530 (2016) Standard Practice Aircraft Structural Integrity Program (ASIP). US, Department of Defense

2. L. Molent, S. A. Barter and R. J. H. Wanhill (2011) The lead crack fatigue lifing framework. International Journal of Fatigue 33 323-331

3. C. Wallbrink, P. Jackson and W. Hu (2011) Crack Growth Rate Curves: Which Part Dominates Life Prediction And When? In: International Committee on Aeronautical Fatigue, Montreal, Canada: May 29th - June 3rd

4. K. F. Walker, Barter, S. A. (2011) The Critical Importance of Correctly Characterising Fatigue Crack Growth Rates in the Threshold Regime. 26th ICAF Symposium 1-3 June pp 249-263

5. S. A. Barter, L. Molent and R. J. H. Wanhill (2012) Typical fatigue-initiating discontinuities in metallic aircraft structures. International Journal of Fatigue (41) 2012 11-22 
6. S. Pearson (1975) Initiation of fatigue cracks in commercial aluminium alloys and the subsequent propgation of very short cracks. Eng. Fract. Mech. $7235-247$

7. J. C. Newman Jr, E. P. Phillips and M. H. Swain (1999) Fatigue-life prediction methodology using small-crack theory. International Journal of Fatigue 21 109-119

8. J. Schijve (2003) Fatigue of Structures and Materials in the 20th Century and the state of the art. International Journal of Fatigue 25 (8) 2003 679-702

9. (2014) West Conshohocken, PA 19428-2959, USA, Standard Test Method for Measurement of Fatigue Crack Growth Rates.

10. M. Liao (2010) Dislocation theroy based short crack model and it's application for aircraft aluminium alloys. Engineering Fracture Mechanics 77 22-36

11. A. Shyam, et al. (2007) Small fatigue crack growth in metallic materials: A model and it's application to engineering alloys. Acta Materialia 55 66066616

12. A. K. Vasudevan, K. Sadananda and G. Glinka (2001) Critical parameters for fatigue damage. International Journal of Fatigue 232001 39-53

13. R. Jones, L. Molent and K. Walker (2012) Fatigue crack growth in a diverse range of materials. Journal of Fatigue 40 43-50

14. M. H. El Haddad, K. N. Smith and T. H. Topper (1979) Fatigue crack propagation of short cracks. Journal of Engineering Materials and Technology, Trans. ASME $10142-46$

15. D. Taylor (2008) The theory of critical distances. UK, Elsevier

16. M. McDonald, L. Molent and A. J. Green (2006) Assessment of Fatigue Crack Growth Prediction Models for F/A-18 Representative Spectra and Material. DSTO-RR-0312, Melbourne, Australia, Defence Science and Technology Organisation

17. S. Barter, M. Burchill and M. Jones (2015) Improving the prediction of small crack growth in 7XXX aluminium alloys In: 28th ICAF Symposium, Helsinki: 3-5 June 2015

18. P. White, S. Barter and L. Molent (2007) Observations of crack path changes caused by periodic underlaods in AA7050-T7451. International Journal of Fatigue 30 (7) 1267-1278

19. S. Barter, P. White and M. Burchill (2016) Fatigue crack path manipulation for crack growth rate measurement. Journal of Engineering Fracture Mechanics 167 224-238

20. J. A. Harter (2014) AFGROW Users Guide and Technical Manual. Lex Tech,

21. M. Burchill, S. Barter and L. H. Chan (2017) Improving fatigue life predictions with a crack growth rate material model based on small crack growth \& legacy data. In: AIAC, Melbourne, Australia: February, 2017

22. M. Burchill, S. A. Barter and M. Jones (2014) The effect of crack growth retardation when comparing constant amplitude to variable amplitude loading in an aluminium alloy. Advanced Materials Research 891-892 948-54

23. P. White, S. A. Barter and C. Wright (2009) Small crack growth rates from simple sequences containing underloads in AA7050-T7451. International Journal of Fatigue 312009 18651874

24. J. Newman and Y. Yamada (2009) Crack-Closure Behavior of 7050 Aluminum Alloy near Threshold Conditions for Wide Range in Load Ratios and Constant Kmax Tests. In: ASTM/ESIS Fatigue and Fracture Mechanics Symposium, Vancouver, CANADA,

25. R. J. H. Wanhill (1994) Flight simulation fatigue crack growth testing of aluminium alloys. Fatigue 161994 99-110 